\title{
Experimental gastritis leads to anxiety- and depression-like behaviors in female but not male rats
}

Jia Luo ${ }^{1,2}$, Tao Wang ${ }^{1}$, Shan Liang ${ }^{1,2}, \mathrm{Xu} \mathrm{Hu}^{1}$, Wei Li ${ }^{1,2}$ and Feng Jin ${ }^{1^{*}}$

\begin{abstract}
Human and animals studies support the idea that there is a gender-related co-morbidity of pain-related and inflammatory gastrointestinal (GI) diseases with psychological disorders. This co-morbidity is the evidence for the existence of Gl-brain axis which consists of immune (cytokines), neural (vagus nerve) and neuroendocrine (HPA axis) pathways. Psychological stress causes disturbances in Gl physiology, such as altered Gl barrier function, changes in motility and secretion, development of visceral hypersensitivity, and dysfunction of inflammatory responses. Whether Gl inflammation would exert impact on psychological behavior is not well established. We examined the effect of experimental gastritis on anxiety- and depression-like behaviors in male and female Sprague-Dawley rats, and evaluated potential mechanisms of action. Gastritis was induced by adding $0.1 \%(\mathrm{w} / \mathrm{v}$ ) iodoacetamide (IAA) to the sterile drinking water for 7 days. Sucrose preference test assessed the depression-like behavior, open field test and elevated plus maze evaluated the anxiety-like behavior. IAA treatment induced gastric inflammation in rats of either gender. No behavioral abnormality or dysfunction of Gl-brain axis was observed in male rats with IAA-induced gastritis. Anxiety- and depression-like behaviors were apparent and the HPA axis was hyperactive in female rats with IAA-induced gastritis. Our results show that gastric inflammation leads to anxiety- and depression-like behaviors in female but not male rats via the neuroendocrine (HPA axis) pathway, suggesting that the Gl inflammation can impair normal brain function and induce changes in psychological behavior in a gender-related manner through the Gl-to-brain signaling.
\end{abstract}

Keywords: Gastrointestinal-brain axis, lodoacetamide-induced gastritis, Anxiety, Depression, Gender difference

\section{Introduction}

The high co-morbidity between gastrointestinal (GI) diseases, including irritable bowel syndrome (IBS), inflammatory bowel disease (IBD) and functional dyspepsia (FD), and psychological symptoms such as depression and anxiety is the evidence for existence of GI-brain axis [1-8]. Many researches on this field have focused on the pathogenic role of psychological stress based on the primary observation that psychological stress induces modifications of motility, secretion, visceral sensitivity, and local inflammatory responses in the GI tract $[9,10]$. However, in recent years a growing body of studies provides compelling evidences to suggest that not only can the brain affect GI

\footnotetext{
* Correspondence: jinfeng@psych.ac.cn

${ }^{1}$ Key Laboratory of Mental Health, Institute of Psychology, Chinese Academy of Sciences, Beijing, China

Full list of author information is available at the end of the article
}

activity, but that the GI activity can also induce changes in brain function [11-13]. There are three potential pathways that have been proposed so far, through which GI signals can be transmitted to and induce changes in brain function: immune (cytokines), neural (vagus nerve) and neuroendocrine (corticosterone/HPA axis) pathways [1,14].

In this study, to examine whether GI inflammation affected psychological behavior, the anxiety- and depressionlike behaviors were assessed following induction of gastritis in Sprague-Dawley rats. Gastritis was induced by adding $0.1 \%(\mathrm{w} / \mathrm{v})$ iodoacetamide (IAA) to the sterile drinking water for 7 days. The activities of the three GI-brain axis pathways through which gastric inflammation may modulate the brain function and behavior were also evaluated. Since these pain-related and inflammatory GI diseases have a considerably higher prevalence in women than in men [15-19], we tested both male and female rats in order to 
reveal any gender difference in the possible impact of gastritis on psychological behavior. Data provided by ample studies in gonadectomy animals propose sex hormone as an obvious candidate to explain the sexual dimorphism in behaviors [20,21]. Therefore, we also measured the plasma levels of 17ß-estradiol and testosterone in female and male rats respectively.

\section{Materials and methods A \\ Animals}

Specific-pathogen-free male and female Sprague-Dawley rats, 8-9 week old, (VITAL RIVER Animal Centre, Beijing, China) were used in the study. All rats were housed individually in wire-mesh cages in animal rooms with controlled temperature at $20 \pm 2^{\circ} \mathrm{C}$, a relative humidity of $50 \%-55 \%$, and a 12:12 h light/ dark cycle. They had free access to standard laboratory rodent chow and fresh sterile drinking water. Four groups of animals were included in the study: control group ( $\mathrm{C}$ group) and iodoacetamidetreated group (IAA group) of male and female rats. Female rats were housed in another room away from male rats.

\section{Experiment protocols}

After two-week acclimatization (day 1-14), IAA groups were treated with iodoacetamide via drinking water for 7 days (day 15-21). The control groups drank the fresh sterile water throughout the whole experiment. The drinking volumes ( $\mathrm{ml} / \mathrm{g}$ body weight) recorded at experiment days 8 and 15 were used for calculation of the drinking volumes during days $1-14$ and 15-21 respectively. Since there is evidence that behavioral test may itself has a gender-related effect on biochemical activity [22], the biochemical markers and psychological behaviors were parallelly assessed in two parts of rats following 7-day IAA treatment. One day after the 7-day IAA treatment period (day 22), each group with 6 rats was sacrificed by decapitation. The trunk blood and gastric tissue were collected, and the brain was removed immediately for further dissection. Simultaneously, a sequence of behavior tests started from day 22 was carried out in each group with 6-8 rats, during which the animals continued to drink either sterile water or water containing IAA. The experimental protocol was approved by the Animal Experiment Ethics Committee of the Institute of Psychology, Chinese Academic of Sciences.

\section{Induction of gastritis}

Iodoacetamide (IAA) was purchased from Sigma Chemical Company, St. Louis, MO, USA. Gastritis was induced by addition of $0.1 \%(\mathrm{w} / \mathrm{v})$ IAA to drinking water for 7 successive days, based on the model described by Karmeli et al. who showed a maximum increase in gastric inflammation and lesion for this period of administration [23]. Since IAA is light sensitive, the light-limiting drink bottles were used, and the IAA-containing drinking water was refreshed every day.

\section{Behavioral tests}

Behavioral tests were conducted in sequential order of sucrose preference test (SPT), open field test (OFT), elevated plus maze (EPM). The SPT examined depressionlike behavior, while OFT and EPM were used to evaluate anxiety-like behavior.

\section{Sucrose preference test (SPT)}

This consisted of a 48 hours training session and a 1 hour test session conducted 24 hours after the training session [13,24]. In the training session, singly housed rats were trained for 48 hours to drink sugar water in a cage containing two bottles, one bottle containing $1 \%$ sucrose solution and another one containing sterile water. The bottles were switched every 12 hours to prevent possible effects of side preference in drinking behavior. Afterwards, only sterile water was provided for 6 hours. Then food and water were withheld from rats for 18 hours. In the test session, rats got access to two bottles with $1 \%$ sucrose solution and water, respectively, for one hour. Sucrose preference was evaluated according to the formula below: Sucrose preference $(\mathrm{SP})=[\mathrm{su}-$ crose intake $(\mathrm{ml}) /($ sucrose intake $(\mathrm{ml})+$ water intake $(\mathrm{ml}))] \times 100$.

\section{Open field test (OFT)}

The open field apparatus consisted of an arena $(100 \mathrm{~cm} \times$ $100 \mathrm{~cm} \times 40 \mathrm{~cm}$ ) made of black polypropylene [25]. Rats were individually placed into the corner of the field, and allowed to explore the arena for 5 minutes. Movements were recorded by a video camera mounted above the center of the arena, and analyzed using the ANY-Maze video tracking system (Stoelting CO, USA).

\section{Elevated plus maze (EPM) test}

The EPM apparatus consisted of a center area $(10 \times 10 \mathrm{~cm})$ with two opposite closed $(10 \mathrm{~cm}$ wide, $50 \mathrm{~cm}$ long, $30 \mathrm{~cm}$ high wall at their sides and the far end) and two opposite open arms (10 cm wide, $50 \mathrm{~cm}$ long) arranged in the shape of a plus. The device was made of opaque black polypropylene and elevated $50 \mathrm{~cm}$ above the floor [26].

Rats were placed individually on the center of the maze facing an open arm and were allowed 5 minutes of free exploration. The movements of the animals during the 5 -minute test period were tracked by a video camera positioned above the center of the maze and were analyzed using ANY-Maze (Stoelting CO, USA) video tracking system. 


\section{Determination of myeloperoxidase (MPO) activity in gastric tissue}

Full-thickness sample of the gastric corpus (100-120 mg) was excised and the gastric MPO activity was determined according to the previously described spectrophotometric technique $[27,28]$. MPO is granule-associated enzyme primarily contained in neutrophils, correlates well with the severity of the inflammation and histological lesion, and its measurement has been widely used as a marker of gastrointestinal inflammation. MPO activity was expressed as units per milligram of wet tissue, where one unit of MPO was defined as the quantity of the enzyme able to convert $1 \mu$ mol hydrogen peroxide to water in 1 minute at room temperature.

\section{Enzyme-linked immunosorbent assay (ELISA) analysis}

The trunk blood was collected and centrifuged $(1500 \times \mathrm{g}$, $10 \mathrm{~min}, 4^{\circ} \mathrm{C}$ ). Plasma was taken and immediately stored at $-80^{\circ} \mathrm{C}$ until assayed. Cytokines including interleukin-6 (IL-6), interferon-gama (INF- $\gamma$ ), and tumor necrosis factoralpha (TNF- $\alpha$ ) (IBL, Minneapolis, USA), as well as sex hormones including 17ß-estradiol and testosterone, and corticosterone (Abcam, Cambridge, UK) in plasma were measured using ELISA kits, according to the manufacturer's instructions.

\section{RNA isolation and reverse transcription}

RNA was isolated from hypothalamus (50-70 mg) using TRNzol reagent according to the manufacturer's instructions (Tiangen Biotech Co. Ltd., Beijing, China). $4 \mu \mathrm{l}$ of total RNA from each sample was converted to doublestranded cDNA using TIANScript Reverse Transcription Kit (Tiangen Biotech Co. Ltd., Beijing, China). Subsequently, $2 \mu \mathrm{l}$ of the resulting cDNA samples were used in the following quantitative real-time PCR (qPCR) for measurement of mRNA expressions of Gapdh (housing keep gene), C-fos, corticotropin-releasing factor ( $\mathrm{Crf}$ ) and glucocorticoid receptor $(\mathrm{Gr})$.

\section{Quantitative real-time polymerase chain reaction (qPCR)}

The qPCR reaction was performed in a Real Time PRC system (Applied Biosystems, model 7300) using SYBR ${ }^{\circledR}$ Premix Ex Taq ${ }^{\text {TM }}$ (Takara Bio, Japan). The primers used in this study were listed in Table 1 . Primers were validated previously to exclude cross reactivity [29-32].

Table 1 Primer sequences used for real-time PCR

\begin{tabular}{|c|c|c|}
\hline Target & Forward (5'- 3') & Reverse $\left(5^{\prime}-3^{\prime}\right)$ \\
\hline$\overline{\text { GAPDH }}$ & ATGACTCTACCCACGGCAAG & TACTCAGCACCAGCATCACC \\
\hline c-fos & CCGACTCCTTCTCCAGCAT & TCACCGTGGGGATAAAGTTG \\
\hline CRF & GTTGAATTTCTTGCAACCGGAG & GACTTCTGTTGAGGTTCCCCAG \\
\hline$R$ & AGGGGAGGGGGAGCGTAATGG & СCTCTGCTGCTTGGAATCTGC \\
\hline
\end{tabular}

Relative quantification was analyzed with the 7300 system SDS software, and the mean $2^{-\Delta C T}$ was calculated for each sample. Results were presented as percentage expression relative to Gapdh.

\section{Statistical analysis}

Results were presented as means \pm standard error of mean (S.E.M). In all statistical comparisons, two-tailed, $p<0.05$, were regarded as significant difference. Statistical evaluation of the results was performed on SPSS 17.0 (SPSS Inc., Chicago, IL, USA) with two-way analysis of variance (ANOVA) to identify gender differences, treatment effects and the interaction between these factors. The homogeneity of variance was analyzed with the Levene test. When the significance was reached with the ANOVA, a post-hoc test (Tukey HSD test) was employed.

\section{Results}

\section{Gastric myeloperoxidase (MPO) activity}

As shown in Figure 1, MPO activity was significantly increased (ANOVA for factor treatment: $F_{(1,20)}=78.59$, $p<0.001)$ in IAA-treated rats as compared with control rats. The IAA-induced increase in MPO activity was similar between male and female rats (ANOVA for factor gender: $\left.F_{(1,20)}=0.265, p>0.05\right)$, whereas female control rats had a greater $(p<0.05) \mathrm{MPO}$ activity than male control rats. The interaction between the factors treatment and gender was significant $\left(F_{(1,20)}=4.81, p<0.05\right)$.

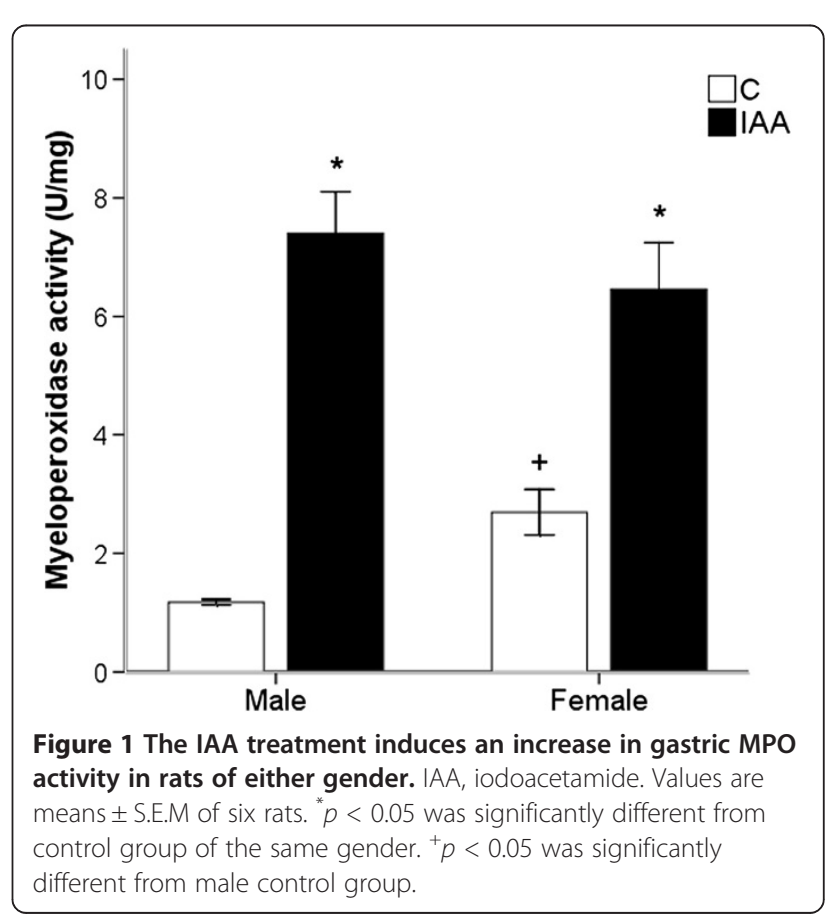




\section{Behavior test for depression-like behavior Sucrose preference test (SPT)}

In the SPT, the sucrose preference was taken as indices of depression. As shown in Figure 2, the IAA treatment significantly reduced the sucrose preference (ANOVA for factor treatment: $\left.F_{(1,24)}=12.79, p<0.01\right)$. Moreover, the interaction between the factors treatment and gender was significant $\left(F_{(1,24)}=13.80, p=0.001\right)$. The sucrose preference was significantly $(p<0.05)$ decreased only in female but not $(p>0.05)$ male IAA-treated rats, while in control rats the sucrose preference did not exhibit any gender difference $(p>0.05)$.

\section{Behavior test for anxiety-like behavior Open field test (OFT)}

In the OFT, the number of entries into, the time spent and the distance traveled in the center zone were taken as indices of anxiety. These parameters were expressed as a percentage of the total entries into, the total time spent and the total distance traveled in the center zone during the 5 min test session.

The Figure 3A demonstrated that the IAA treatment had no effect on the number of entries into the central zone (ANOVA for factor treatment: $F_{(1,24)}=3.49, p>0.05$ ). The number of entries into the central zone was similar between IAA-treated and control rats of the same gender. The IAA treatment significantly reduced the time spent and distance traveled in the central zone (ANOVA for factor treatment: $F_{(1,24)}=14.91, p=0.001 ; F_{(1,24)}=7.98$,

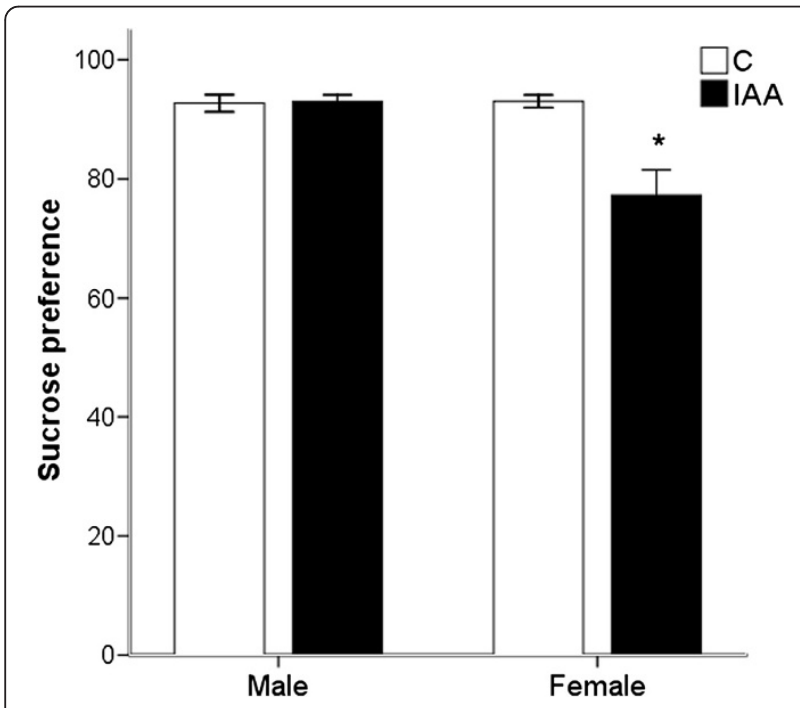

Figure 2 The female but not male rats with IAA-induced gastritis develop depression-like behavior. The sucrose preference test was used to measure depression. The sucrose preference correlated negatively with the depression state. IAA, iodoacetamide. Values are means \pm S.E.M. ${ }^{*} p<0.05$ was significantly different from control group of the same gender. $\mathrm{N}=8 \mathrm{rats} / \mathrm{male}$ group, $\mathrm{N}=6 \mathrm{rats} / \mathrm{female}$ group. $p<0.01)$. The interaction between the factors treatment and gender was significant (central zone time: $F_{(1,24)}=$ 6.67, $p<0.05$; central zone distance: $F_{(1,24)}=4.62$, $p<0.05)$. However, the central zone time and distance were decreased $(p<0.01 ; p<0.01)$ only in female but not male IAA-treated rats, while female control rats spent significantly $(p<0.001 ; p<0.01)$ more time and distance in the central zone than male control rats.

\section{Elevated plus maze (EPM)}

In the EPM, the number of entries into, the time spent and the distance traveled in the open arms were taken as indices of anxiety. These parameters were expressed as a percentage of the total entries into, the total time spent and the total distance traveled in any arm during the 5 min test session.

In Figure 3B, the IAA treatment had no effect on the number of entries into the open arms (ANOVA for factor treatment: $\left.F_{(1,24)}=4.18, p>0.05\right)$. The number of entries into the open arms was similar between IAA-treated and control rats of the same gender. The IAA treatment significantly reduced the time spent and distance traveled in the open arms (ANOVA for factor treatment: $F_{(1,24)}=6.88$, $\left.p<0.05 ; F_{(1,24)}=8.67, p<0.01\right)$. The interaction between the factors treatment and gender was significant (open arm time: $F_{(1,24)}=16.23, p<0.001$; open arm distance: $F_{(1,24)}=$ 23.73, $p<0.001)$. However, the open arm time and distance were decreased $(p<0.01 ; p<0.001)$ only in female but not in male IAA-treated rats, while in control rats the time spent and distance traveled in open arms did not exhibit any gender difference $(p>0.05 ; p>0.05)$.

\section{Plasma levels of pro-inflammatory cytokines}

Male and female control rats did not differ in plasma concentrations of IL-6 $(47.91 \pm 2.62 \mathrm{pg} / \mathrm{ml}$ vs $40.80 \pm 2.71 \mathrm{pg} /$ $\mathrm{ml}, p>0.05)$, TNF- $\alpha(134.10 \pm 11.84 \mathrm{pg} / \mathrm{ml}$ vs $123.88 \pm$ $8.26 \mathrm{pg} / \mathrm{ml}, p>0.05)$ and INF- $\gamma(898.68 \pm 77.66 \mathrm{pg} / \mathrm{ml} v s$ $805.09 \pm 51.85 \mathrm{pg} / \mathrm{ml}, p>0.05)$. Furthermore, the IAA treatment had no effect on plasma levels of IL-6, TNF- $\alpha$ and INF- $\gamma$ (ANOVA for factor treatment: $F_{(1,20)}=0.27$, $p>0.05 ; F_{(1,20)}=0.29, p>0.05 ; F_{(1,20)}=1.66$, $p>0.05)$. The concentrations of IL-6, TNF- $\alpha$ and INF- $\gamma$ did not differ between IAA-treated and control rats of the same gender. Plasma levels of IL-6, TNF- $\alpha$ and INF- $\gamma$ in male IAA-treated rats were $49.64 \pm 3.91 \mathrm{pg} / \mathrm{ml}, 118.18 \pm$ $8.18 \mathrm{pg} / \mathrm{ml}$ and $830.98 \pm 44.98 \mathrm{pg} / \mathrm{ml}$, in female IAAtreated rats were $42.41 \pm 3.50 \mathrm{pg} / \mathrm{ml}, 149.95 \pm 9.00 \mathrm{pg} / \mathrm{ml}$ and $923.51 \pm 40.11 \mathrm{pg} / \mathrm{ml}$.

\section{C-fos mRNA expression in hypothalamus}

The hypothalamic $C$-fos expressions were similar between male and female control rats $(0.54 \pm 0.09 \%$ vs $0.49 \pm 0.13 \%, p>0.05)$. The IAA treatment had no effect on hypothalamic C-fos expression (ANOVA for factor 


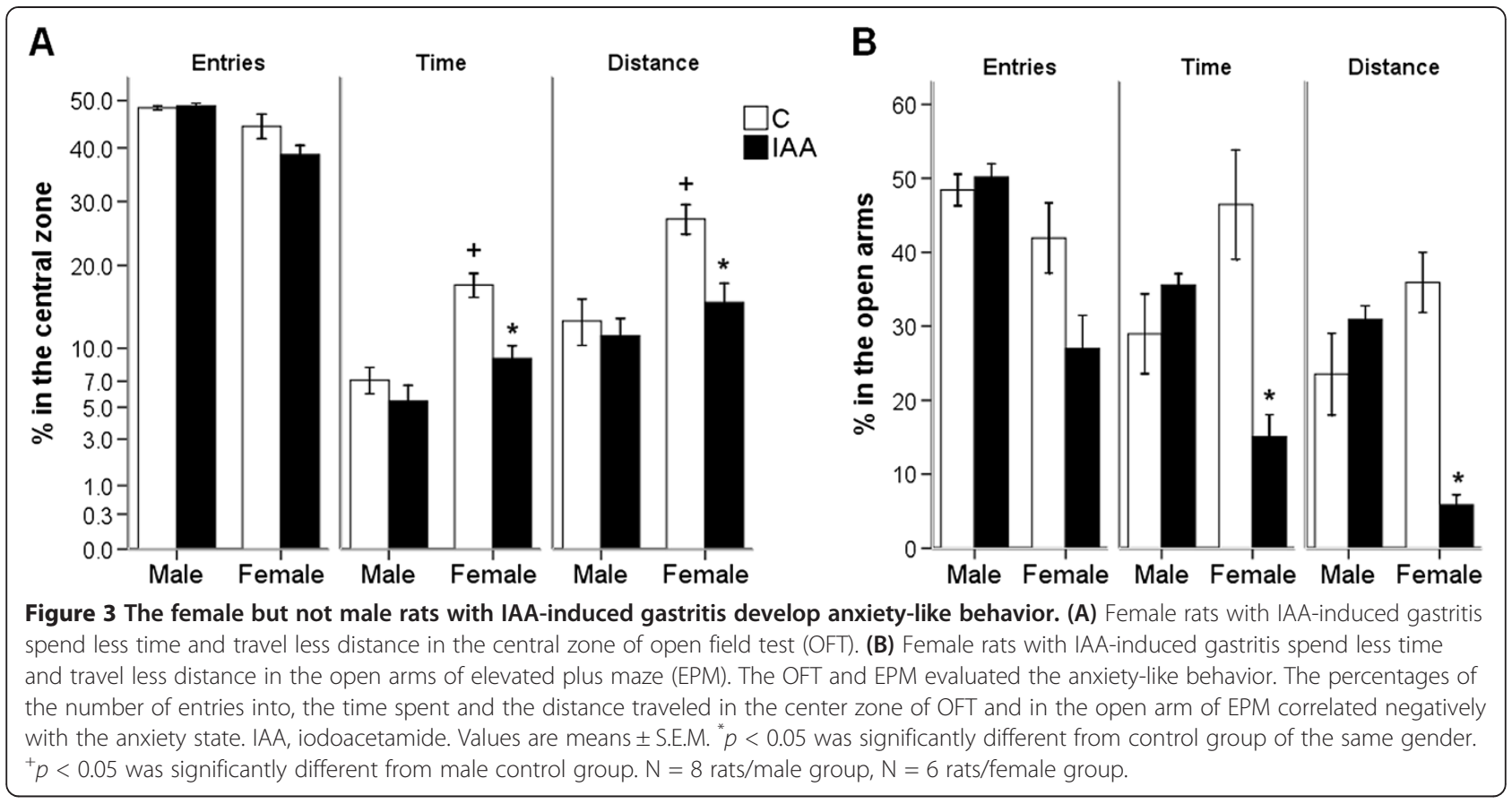

treatment: $\left.F_{(1,20)}=2.723, p>0.05\right)$. The interaction between the factors treatment and gender was not significant.

The activity of hypothalamic-pituitary-adrenal (HPA) axis Corticotropin-releasing factor (Crf) mRNA expression in hypothalamus

As shown in Figure 4A, the IAA treatment significantly increased the hypothalamic Crf expression (ANOVA for factor treatment: $\left.F_{(1,20)}=14.56, p=0.001\right)$. The interaction between the factors treatment and gender was significant $\left(F_{(1,20)}=13.52, p=0.001\right)$. The hypothalamic Crf expression was only increased $(p=0.001)$ in female but not in male IAA-treated rats, while male and female control rats did not differ in hypothalamic Crf mRNA expression $(1.35 \pm 0.23 \%$ vs $0.97 \pm 0.15 \%, p>0.05)$.

\section{Glucocorticoid receptor (Gr) mRNA expression in hypothalamus}

The Figure 4B revealed that the hypothalamic Gr mRNA expressions were significantly greater in female than in male control rats $(1.08 \pm 0.11 \%$ vs $0.60 \pm 0.05 \%, p<0.01)$. The interaction between the factors treatment and gender was significant $\left(F_{(1,20)}=11.85, p<0.01\right)$. Furthermore, it was found that IAA treatment induced a drop $(p<0.001)$ in $\mathrm{Gr}$ expression only in female rats, but not in male rats.

\section{Plasma levels of corticosterone (CORT)}

In Figure 4C, IAA treatment significantly reduced (ANOVA for factor treatment: $\left.F_{(1,20)}=17.91, p<0.001\right)$ plasma CORT levels. The interaction between the factors treatment and gender was significant $\left(F_{(1,20)}=16.52, p=0.001\right)$. The CORT levels were decreased $(p=0.001)$ only in female but not $(p>0.05)$ male IAA-treated rats, whereas female control rats had a higher CORT levels than male control rats $(285.12 \pm 5.32 \mathrm{ng} / \mathrm{ml}$ vs $264.38 \pm 6.38 \mathrm{ng} / \mathrm{ml}, p<0.05)$.

\section{Plasma levels of sex hormones: $17 ß$-estradiol and} testosterone

IAA treatment induced a reduction $(p<0.01)$ in plasma $17 \AA$-estradiol levels in female rats (Figure $5 \mathrm{~A}$ ). Figure $5 \mathrm{~B}$ showed that male rats treated with IAA had a higher testosterone level than male controls $(194.35 \pm 6.37 \mathrm{pg} / \mathrm{ml}$ vs $141.99 \pm 6.56 \mathrm{pg} / \mathrm{ml}, p<0.001)$.

\section{Daily drank water}

Rats significantly drank less (ANOVA for factor treatment: $\left.F_{(1,20)}=131.69, p<0.001\right)$ IAA water than the normal drinking water. The IAA-induced reduction in drank water was similar between male and female rats (ANOVA for factor gender: $F_{(1,20)}=0.928, p>0.05$ ), while during acclimatization period (day 1-14), the daily drank water was not significantly different $(0.160 \pm$ $0.011 \mathrm{ml} / \mathrm{g}$ vs $0.139 \pm 0.011 \mathrm{ml} / \mathrm{g}, p>0.05$ ) between male and female control rats. As a result, during day 15-21, male and female rats drank similar volume of watercontaining IAA $(0.0528 \pm 0.003 \mathrm{ml} / \mathrm{g} \quad$ vs $0.0578 \pm$ $0.003 \mathrm{ml} / \mathrm{g}, p>0.05)$. The interaction between the factors treatment and gender was not significant $\left(F_{(1,20)}=\right.$ 2.429, $p>0.05)$. 


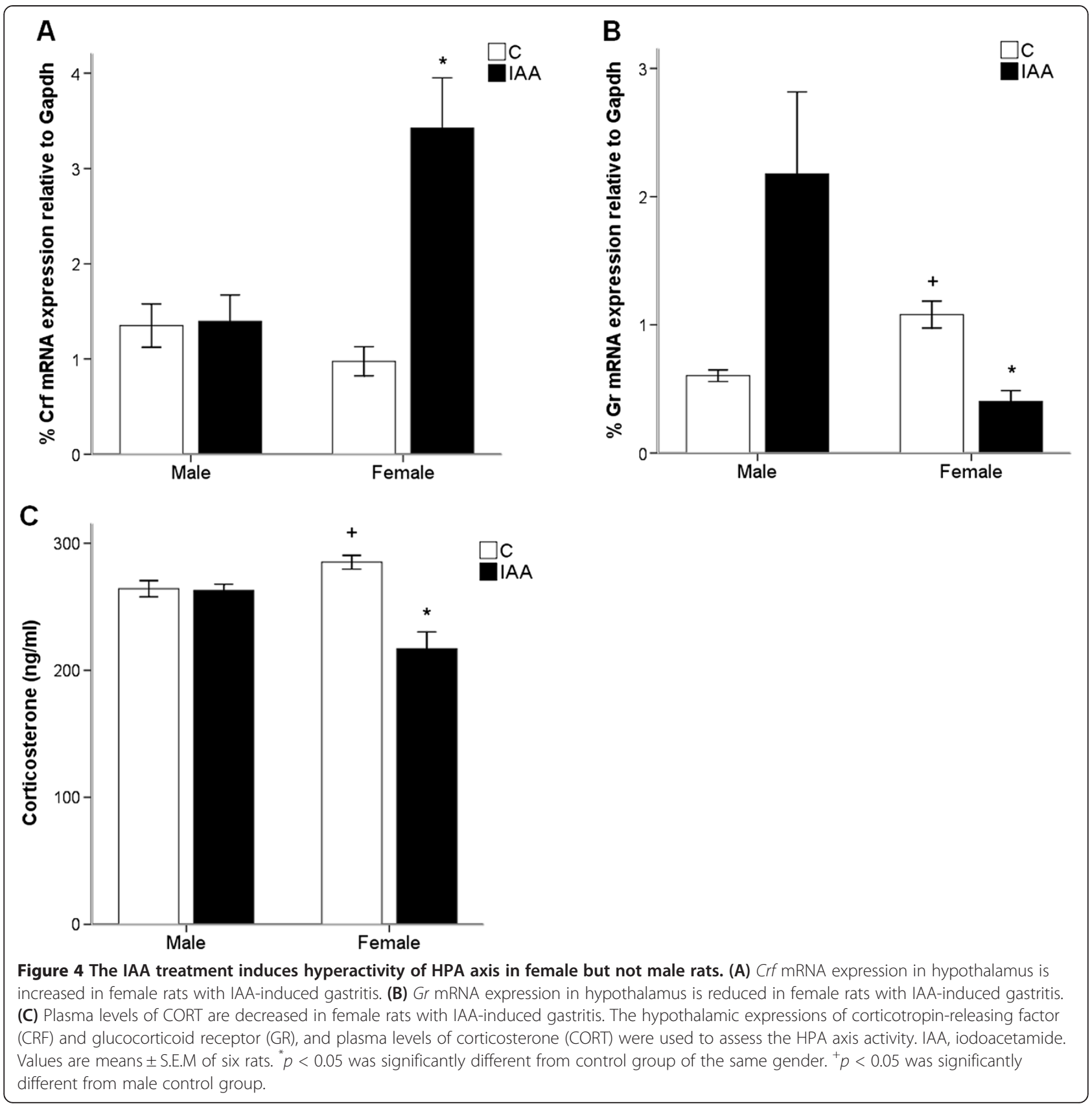

\section{Discussion}

Effect of gastric inflammation on psychological behaviors in male and female rats

In view of the growing evidence that pain-related and inflammatory GI diseases are linked to anxiety and depression symptoms, the overall aim of our study was to test a possible relationship between gastric inflammation and psychological behaviors in rats. While it has previously been shown that psychological stressors such as experimentally induced depression- and anxiety-like phenotypes enhance the vulnerability to intestinal inflammation [33-35], we here explore whether GI inflammation has an impact on anxiety- and depressionlike behaviors in rats.

The IAA added to drinking water at a concentration of $0.1 \%$ for 7 days has been previously shown to elicit murine gastric inflammation. In the present study we observed that the gastric inflammation was successfully induced by IAA treatment in rats of either gender, as assessed by increased MPO activities in IAA-treated rats. A potential drawback of IAA-induced gastritis model is the significant reduction of water intake [36,37]. Nonetheless, previous reported analysis of the circadian activity patterns revealed that IAA reduced drinking, feeding 

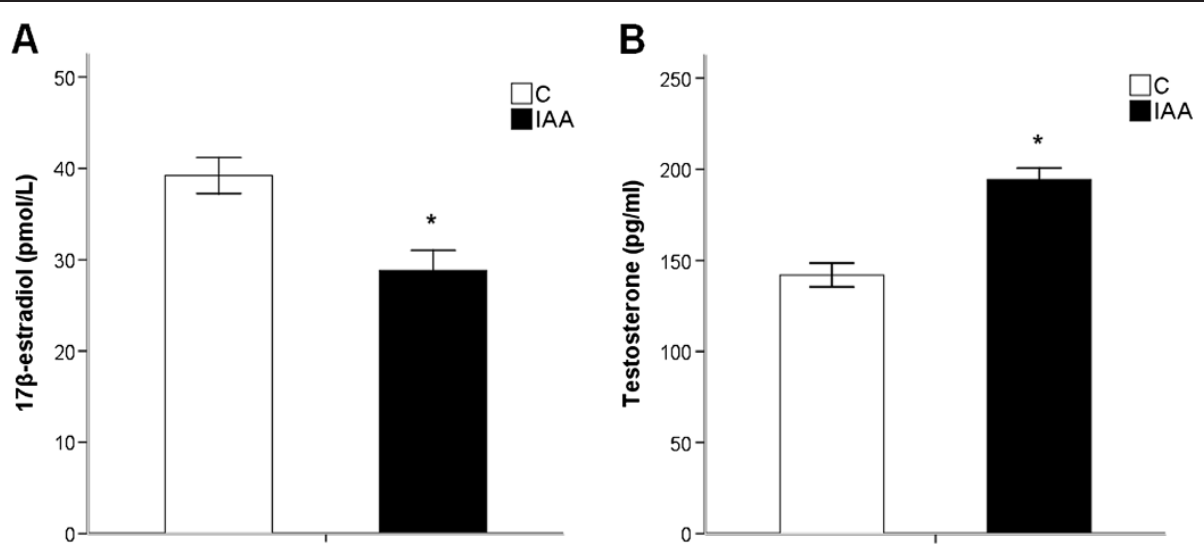

Figure 5 The IAA treatment causes changes in sex hormones in rats of either gender. (A) Plasma levels of 17ß-estradiol are decreased in female rats with IAA-induced gastritis. (B) Plasma levels of testosterone are increased in male rats with IAA-induced gastritis. IAA, iodoacetamide. Values are means \pm S.E.M of six rats. ${ }^{*} p<0.05$ was significantly different from control group of the same gender.

and locomotor activity only during the dark phase to a significant extent, suggesting that the reduction of water intake is not primarily taste-related but, together with the decrease in feeding and locomotor activity, reflects a behavioral consequence of gastritis [22]. The normal appetite for sucrose and water should be reserved in gastritis rats. Moreover, the sucrose preference test has been used extensively to measure anhedonia, a core symptom of depression, in mild stress models of depression [38-40]. Strekalova et al. [24] found that anhedonia was associated with analogues of depressive symptoms, such as increased floating during forced swimming and decreased exploration of novelty. Thus, the sucrose preference of IAA-treated rats reflects their depression scores.

The significant interaction between the factors treatment and gender on anxiety- and depression-like behaviors may indicate that the IAA-induced gastritis has a gender-related effect on psychological behaviors. The female rats with IAA-induced gastritis exhibited anxietyand depression-like behaviors as assessed in SPT, OPT and EPM tests. Nevertheless, IAA treatment failed to affect the psychological behaviors in male rats. Although it could be argued that IAA treatment failed to reduce the time and distance that male rats spent and traveled in the central zone of the open field, because male control rats spent significantly less time and traveled less distance in the central zone than female control rats, this argument is not applicable to the time spent and the distance traveled in the open arms of EPM in which male and female control rats did not significantly differ.

The gender-related behavioral response to experimental gastritis is not an unexpected finding. Firstly, there is clinical evidence for a gender-related co-morbidity of functional dyspepsia with anxiety and depression as we have discussed before [6,8,19]. Secondly, the IAA-induced gastritis in rats has previously been shown to elicit hypersensitivity to both mechanical and chemical noxious stimulation of the stomach, and has been proposed to represent an experimental model of functional dyspepsia $[13,37,41]$.

The gastric inflammation could influence the psychological behavior via the three potential pathways of GI-brain axis including immune, vagal nerve and neuroendocrine pathways. The gender-related increase in anxiety and depression due to gastritis went in parallel with the changes in the three GI-to-brain pathways. The IAA treatment had no effect on pro-inflammatory cytokines levels in plasma. In male rats, a normal behavior is in line with the lack of effect of IAA treatment on proinflammatory cytokines. However, the lack of effect of IAA treatment on plasma levels of pro-inflammatory cytokines (IL-6, TNF- $\alpha$ and INF- $\gamma$ ) in female rats may suggest that the gender-related impact of gastric inflammation on psychological behaviors is not mediated by the circulating immune pathway. The vagus nerve is another route for the GI-to-brain signaling. When the vagus nerve is activated, information carried by vagal afferent from gastrointestinal tract is transmitted to the nucleus tractus solitaries (NTS), the site of primary afferent termination of the vagus nerve - before areas involved in the stress response such as the paraventricular nucleus of the hypothalamus [42-44]. It has been shown that stimuli induces expression of c-fos expression in neurons in the NTS, and also in the PVN of hypothalamus $[45,46]$. Moreover, data provided by studies in vagotomy animals showed that the stress-induced c-fos expression in PVN was reduced by vagotomy [47-49], suggesting the neuronal activity in PVN can reflect the vagus nerves activity.

Expression of c-fos, either C-fos mRNA or c-Fos protein levels (c-Fos protein-positive neurons), is an indirect 
marker of neuronal activity because c-fos is often expressed when neurons fire action potentials. Emerging body of literature presents ample evidences that $C$-fos mRNA expression can be used as a tool to assess neuronal activation [50-55]. Moreover, data from previous studies have shown that the $C$-fos mRNA expression was significantly correlated with c-Fos protein expression in neurons of brain regions [56-59]. Therefore, we evaluated the vagus nerve activity by measuring the mRNA expression of $C$-fos in the hypothalamus. There is a nonsignificant interaction between the treatment and gender on hypothalamic $C$-fos expressions. No significant difference in hypothalamic $C$-fos mRNA expressions between female rats with IAA-induced gastritis and female controls may indicate that the vagal nerves do not mediate the gender-related impact of gastric inflammation on psychological behavior in the present study. Nevertheless, it is important to emphasize that the entire hypothalamus may be a relatively extensive size of brain region compared to $\mathrm{PVN}$, and may not be effective in the assessment of vagus afferent activity. Therefore, these results must be interpreted with caution. The observed lack of effect of IAA treatment on hypothalamic c-fos expression seems to be in contrast to the many reports that describe an induction of c-fos expression in a variety of brain areas in response to a wide range of stressors, including restraint, swimming, audiogenic noise and immune challenge [60-63]. However, these stressors that induce c-fos expression are acute stressors. Data from ample studies have suggested that habituation to chronic stress could induce the lack of stress-induced c-fos expression in the PVN of hypothalamus [64-67]. Tan et al. [64] have shown that expression of c-fos in the hypothalamic PVN region of the brain was induced and reached a peak at 0.5 hours for $C$-fos mRNA and 4 hours for c-Fos protein, but disappeared at 2 hours for C-fos mRNA and 16 hours for c-Fos protein during continuous restraint stress. Moreover, despite the lack of effect of chronic stress on c-fos expression in the PVN, the CRF expression in PVN and plasma CORT levels were found to be markedly changed during chronic stress $[64,68,69]$. This dissociation between c-fos and CRF expression in PVN during chronic stress is in line with the results of the current study that the 7-day-IAA induced gastritis causes gender-related alterations in hypothalamic mRNA expressions of $\mathrm{Crf}$ and $\mathrm{Gr}$ and CORT levels in plasma, but had no effect on hypothalamic C-fos mRNA expression.

Either neural excitatory input to the PVN (represented primarily by c-fos expression) or the ability of cells in the PVN to respond to that input (represented primarily by CRF expression) could activate the HPA axis negative feedback [70]. Double-labelling studies have shown that the majority of cells in the PVN that express c-Fos in response to stressful stimuli can also express CRF [71]. The dissociation between hypothalamic C-fos and Crf mRNA expressions observed in our study may indicate that dysregulation of HPA axis induced by gastritis stress is not a result of increased excitatory neural input to the PVN, but instead depends on some direct effect of gastritis on cells intrinsic to the HPA axis. Similar results were reported in the Sprague-Dawley rat following restraint stress with glucocorticoid pretreatment [70].

The hypothalamic-pituitary-adrenal (HPA) axis plays a prominent role in the neuroendocrine route for the GIto-brain signaling. The HPA axis activation is a homeostatic mechanism that is triggered by a physical or psychological stress to release corticotropin-releasing factor (CRF) and terminated by the negative feedback action that elevations in circulating CORT inhibit the HPA axis by acting via the glucocorticoid receptor (GR) [72]. The significant interaction between the factors treatment and gender on plasma levels of corticosterone and hypothalamic mRNA expressions of $\mathrm{Gr}$ and $\mathrm{Cr} f$ may suggest that the IAA-induced gastritis has a genderrelated effect on the HPA axis activity. The HPA axis activity was altered in female but not male rats with IAA-induced gastritis, as reflected by decreases in hypothalamic Gr mRNA expression and blood CORT levels, and an increase in hypothalamic $C r f$ mRNA expression. These alterations are likely to indicate a hyperactivity of HPA axis due to reduced sensitivity to the negative feedback action of CORT. HPA axis hyperactivity is a consistent finding among patients with major depression disorder [73], and anxiety disorders including panic disorder [74], social anxiety disorder [75] and generalized anxiety disorder [76]. Although it could be argued that IAA treatment failed to reduce the hypothalamic $\mathrm{Gr}$ mRNA expression and plasma CORT levels in male rats, because the hypothalamic $G r$ mRNA expression and plasma CORT levels were significantly less in male than in female control rats, this argument is not applicable to the hypothalamic $C r f$ mRNA expression in which male and female control rats did not significantly differ.

Hyperactivity of HPA axis is primarily characterized by an elevation in central CRF expression which also has been demonstrated to play a prominent role in the etiology of anxiety and depression. Intracerebroventricular administration of CRF reduces the open arm exploration in the EPM and also has anxiogenic effect in other anxiety tests [77]. In clinical studies, individuals with depression, anxiety or suicide exhibit more CRF neurons in hypothalamus than normal individuals [78]. Altogether, the gastric inflammation, the hyperactivity of HPA axis, in combination with the anxiety- and depression-like behaviors in female IAA-treated rats suggest that gastric inflammation has a gender-related 
impact on psychological behaviors via neuroendocrine (HPA axis) pathway.

Rats developed gastric inflammation following 7-day IAA treatment, since the IAA treatment increased the gastric MPO levels in rats of either gender. Furthermore, a significant interaction between the factors treatment and gender in MPO activity may suggest there is a gender difference in sensitivity of IAA-induced gastritis. Although female control rats have a higher MPO levels than male control rats, the IAA treatment still significantly increases the MPO activity in both genders. It may suggest that female rats are more vulnerable to IAA-induced gastritis than male rats. This gender difference in sensitivity of IAA-induced gastritis is consistent with the clinical findings that GI disorder has a considerably higher prevalence in women than in man [15-17]. Therefore, we consider that the gender-related effect of gastritis on anxiety and depression as well as HPA axis activity may be related to the sensitivity to gastritis which was greater in female than in male rats.

\section{Association between sex hormones and the gender-related anxiety- and depression-like behaviors}

Data from animal and clinical studies may also provide some evidences for clarifying the mechanism by which gastric inflammation affects the HPA axis activity and psychological behaviors in a gender-related manner. There is an ample body of literatures that propose the sex hormone as an obvious candidate to explain the behavioral and physiological gender differences [20,21,79].

The sex hormones in female and male rats respectively are $17 ß$-estradiol and testosterone which are demonstrated to modulate the HPA axis response to stressors. In the rodent, the HPA axis responses to endotoxin and to IL-1 are enhanced by gonadectomy and attenuated by estradiol and testosterone replacement [80]. Data from clinical study have also shown that following a precipitous decline in estradiol levels during pregnancy, postpartum women experience greater HPA axis response to stressors [81]. Therefore, in our study, a decline in estradiol level in female IAAtreated rats may lead to an enhanced HPA axis response to gastric inflammation, while an increase in testosterone level in male IAA-treated rats may reserve a normal HPA axis response to gastric inflammation.

Furthermore, since the HPA axis activity has been shown to regulate psychological behaviors, the alterations in sex hormones may be relevant to the gender-related anxietyand depression-like behaviors in rats with IAA-induced gastritis. Data from previous studies have provided evidences for an association between decreased sex hormones and increased susceptibility to anxiety and depression. Postpartum depression, as well as premenstrual syndrome, premenstrual dysphoric disorder and menopause depression are all associated with a drop in circulating estrogen [81].
In addition, men with hypogonadism, a condition where the body produces no or low testosterone, suffer increased levels of depression and anxiety, while testosterone replacement therapy has been shown to effectively improve mood $[82,83]$.

It is well known that cyclical female sex hormone variation has a profound effect on behavioral and neurochemical parameters. Although this can be important, the short duration of the estrous cycle in rats coupled with the duration of the study and the fact that female rats housed in the same room can phase into the same estrous cycle stage [84] would most likely result in not having a differential predominance of animals in any one particular phase of the cycle across groups [85], and exclude the possibility of confounding behavioral effects of different phases of the cycle during the same testing sessions [86-89].

\section{Conclusions}

In summary, our results show that the IAA-induced gastric inflammation leads to anxiety- and depression-like behaviors in female but not male rats via the neuroendocrine pathway, suggesting GI inflammation has a gender-related impact on psychological behavior and providing evidence for the existence of GI-to-brain signaling. This gender-related behavioral effect of gastric inflammation may be related to the different sensitivity to gastritis and the changes in sex hormones. Further studies are required to define how these changes, that happen locally in GI, at the molecular level contribute to the regulation of brain function and behavior in a gender-related manner.

\section{Abbreviations}

IAA: lodoacetamide; GI: Gastrointestinal; IBS: Irritable bowel syndrome; IBD: Inflammatory bowel disease; ELISA: Enzyme-linked immunosorbent assay; qPCR: Quantitative real-time polymerase chain reaction;

MPO: Myeloperoxidase; SPT: Sucrose preference test; EPM: Elevated plus maze; OPT: Open field test; HPA: Hypothalamic-pituitary-adrenal;

CRF: Corticotropin-releasing factor; GR: Glucocorticoid receptor; CORT: Corticosterone.

\section{Competing interests}

The authors declare that they have no competing interests.

\section{Author's contributions}

$J L$ analyzed, interpreted the data and drafted the manuscript; $J$ and $F J$ contributed to the study concept and design; JL, TW, SL and XH performed the research and took care of the acquisition and analysis of data; $J \mathrm{~L}$ and $\mathrm{WL}$ did critical revision of the manuscript for important intellectual content; TW, $\mathrm{XH}$ and FJ provided administrative, technical, or material support; TW, SL, XH and $\mathrm{WL}$ contributed essential reagents or tools; FJ supervised the study. All authors read and approved the final manuscript.

\section{Author details}

'Key Laboratory of Mental Health, Institute of Psychology, Chinese Academy of Sciences, Beijing, China. ${ }^{2}$ University of Chinese Academy of Sciences, Beijing, China.

Received: 17 July 2013 Accepted: 10 December 2013

Published: 17 December 2013 
References

1. Mayer EA: Gut feelings: the emerging biology of gut-brain communication. Nat Rev Neurosci 2011, 12:453-466.

2. Cryan JF, O'Mahony SM: The microbiome-gut-brain axis: from bowel to behavior. Neurogastroenterol Motil 2011, 23:187-192.

3. Suzana Tosic-Golubovic SM, Aleksandar N, Dusan L, Gordana N: Irritable bowel syndrome, anxiety, depression and personality characteristics. Psychiatr Danub 2010, 22:418-424.

4. Addolorato G, Mirijello A, D’Angelo C, Leggio L, Ferrulli A, Abenavoli L, Vonghia L, Cardone S, Leso V, Cossari A, Capristo E, Gasbarrini G: State and trait anxiety and depression in patients affected by gastrointestinal diseases: psychometric evaluation of 1641 patients referred to an internal medicine outpatient setting. Int J Clin Pract 2008, 62:1063-1069.

5. Modabbernia M-J, Mansour-Ghanaei F, Imani A, Mirsafa-Moghaddam S-A Sedigh-Rahimabadi M, Yousefi-Mashhour M, Joukar F, Atrkar-Roushan Z, Bidel S: Anxiety-depressive disorders among irritable bowel syndrome patients in Guilan. Iran. BMC Res Notes 2012, 5:112.

6. Van Oudenhove L, Vandenberghe J, Geeraerts B, Vos R, Persoons P, Fischler B, Demyttenaere $\mathrm{K}$, Tack J: Determinants of symptoms in functional dyspepsia: gastric sensorimotor function, psychosocial factors or somatisation? Gut 2008, 57:1666-1673.

7. Häuser WJK, Klump B, Hinz A: Anxiety and depression in patients with inflammatory bowel disease: comparisons with chronic liver disease patients and the general population. Inflamm Bowel Dis 2011, 17:621-632.

8. Filipović BF, Randjelovic T, Ille T, Markovic O, Milovanović B, Kovacevic N, Filipović BR: Anxiety, personality traits and quality of life in functional dyspepsia-suffering patients. Eur J Intern Med 2013, 24:83-86.

9. Tach $X E$, Tache $Y$, Bonaz B: Corticotropin-releasing factor receptors and stress-related alterations of gut motor function. J Clin Invest 2007, 117:33-40.

10. Taché $Y$, Perdue MH: Role of peripheral CRF signalling pathways in stressrelated alterations of gut motility and mucosal function. Neurogastroenterol Motil 2004, 16:137-142.

11. Mayer EA, Tillisch K, Bradesi S: Review article: modulation of the brain-gut axis as a therapeutic approach in gastrointestinal disease. Aliment Pharmacol Ther 2006, 24:919-933.

12. Bercik P, Verdu EF, Foster JA, Macri J, Potter M, Huang X, Malinowski $P$, Jackson W, Blennerhassett P, Neufeld KA, Lu J, Khan WI, Corthesy-Theulaz I, Cherbut C, Bergonzelli GE, Collins SM: Chronic gastrointestinal inflammation induces anxiety-like behavior and alters central nervous system biochemistry in mice. Gastroenterology 2010, 139:2102-2112. e2101.

13. Liu L, Li Q, Sapolsky R, Liao M, Mehta K, Bhargava A, Pasricha PJ: Transient gastric irritation in the neonatal rats leads to changes in hypothalamic CRF expression, depression- and anxiety-like behavior as adults. PLOS ONE 2011, 6:e19498.

14. Cryan JF, Dinan TG: Mind-altering microorganisms: the impact of the gut microbiota on brain and behaviour. Nat Rev Neurosci 2012, 13:701-712.

15. Heitkemper M, Jarrett M: Irritable bowel syndrome: does gender matter? J Psychosom Res 2008, 64:583-587.

16. Cain K, Jarrett M, Burr R, Rosen S, Hertig V, Heitkemper M: Gender differences in gastrointestinal, psychological, and somatic symptoms in irritable bowel syndrome. Dig Dis Sci 2009, 54:1542-1549.

17. Heitkemper MM, Jarrett ME: Update on irritable bowel syndrome and gender differences. Nutr Clin Pract 2008, 23:275-283.

18. Lesuis N, Befrits R, Nyberg F, van Vollenhoven R: Gender and the treatment of immune-mediated chronic inflammatory diseases: rheumatoid arthritis, inflammatory bowel disease and psoriasis: an observational study. BMC Med 2012, 10:82

19. Welén K, Faresjö Å, Faresjö T: Functional dyspepsia affects women more than men in daily life: a case-control study in primary care. Gend Med 2008 5:62-73

20. Shansky RM, Glavis-Bloom C, Lerman D, McRae P, Benson C, Miller K, Cosand L, Horvath TL, Arnsten AFT: Estrogen mediates sex differences in stress-induced prefrontal cortex dysfunction. Mol Psychiatry 2003, 9:531-538.

21. Gillies GE, McArthur S: Estrogen actions in the brain and the basis for differential action in men and women: a case for sex-specific medicines. Pharmacol Rev 2010, 62:155-198.

22. Painsipp $E$, Wultsch $T$, Shahbazian A, Edelsbrunner M, Kreissl MC, Schirbel A, Bock E, Pabst MA, Thoeringer CK, Huber HP, Holzer P: Experimental gastritis in mice enhances anxiety in a gender-related manner. Neuroscience 2007, 150:522-536.
23. Karmeli F, Okon E, Rachmilewitz D: Sulphydryl blocker induced gastric damage is ameliorated by scavenging of free radicals. Gut 1996 38:826-831

24. Strekalova T, Spanagel R, Bartsch D, Henn FA, Gass P: Stress-induced anhedonia in mice is associated with deficits in forced swimming and exploration. Neuropsychopharmacology 2004, 29:2007-2017.

25. Nosek K, Dennis K, Andrus B, Ahmadiyeh N, Baum A, Woods L, Redei E: Context and strain-dependent behavioral response to stress. Behav Brain Funct 2008, 4:23.

26. Walf AA, Frye CA: The use of the elevated plus maze as an assay of anxiety-related behavior in rodents. Nat Protoc 2007, 2:322-328.

27. Barbara G, Vallance BA, Collins SM: Persistent intestinal neuromuscular dysfunction after acute nematode infection in mice. Gastroenterology 1997, 113:1224-1232.

28. Graff G, Gamache DA, Brady MT, Spellman JM, Yanni JM: Improved myeloperoxidase assay for quantitation of neutrophil influx in a rat model of endotoxin-induced uveitis. J Pharmacol Toxicol 1998, 39:169-178.

29. Jasnow AM, Schulkin J, Pfaff DW: Estrogen facilitates fear conditioning and increases corticotropin-releasing hormone mRNA expression in the central amygdala in female mice. Horm Behav 2006, 49:197-205.

30. Miyakoshi T, Kajiya H, Miyajima K, Takei M, Tobita M, Takekoshi S, Osamura RY: The expression of Wnt4 is regulated by estrogen via an estrogen receptor alpha-dependent pathway in rat pituitary growth hormoneproducing cells. Acta Histochem Cytoc 2009, 42:205-213.

31. Marini F, Pozzato C, Andreetta V, Jansson B, Arban R, Domenici E, Carboni L: Single exposure to social defeat increases corticotropin-releasing factor and glucocorticoid receptor mRNA expression in rat hippocampus. Brain Res 2006, 1067:25-35.

32. Li J, Swope D, Raess N, Cheng L, Muller EJ, Radice GL: Cardiac tissuerestricted deletion of plakoglobin results in progressive cardiomyopathy and activation of $\beta$-catenin signaling. Mol Cell Biol 2011, 31:1134-1144.

33. Varghese AK, Verdú EF, Bercik P, Khan WI, Blennerhassett PA, Szechtman H, Collins SM: Antidepressants attenuate increased susceptibility to colitis in a murine model of depression. Gastroenterology 2006, 130:1743-1753.

34. Bonaz BL, Bernstein CN: Brain-Gut interactions in inflammatory bowel disease. Gastroenterology 2013, 144:36-49.

35. Mawdsley JE, Rampton DS: Psychological stress in IBD: new insights into pathogenic and therapeutic implications. Gut 2005, 54:1481-1491.

36. Piqueras L, Corpa JM, Martínez J, Martínez V: Gastric hypersecretion associated to iodoacetamide-induced mild gastritis in mice. Naunyn Schmiedebergs Arch Pharmacol 2003, 367:140-150.

37. Ozaki N, Bielefeldt K, Sengupta JN, Gebhart GF: Models of gastric hyperalgesia in the rat. Am J Physio/ Gastrointest Liver Physiol 2002, 283:G666-G676.

38. Salazar A, Gonzalez-Rivera BL, Redus L, Parrott JM, O'Connor JC: Indoleamine 2,3-dioxygenase mediates anhedonia and anxiety-like behaviors caused by peripheral lipopolysaccharide immune challenge. Horm Behav 2012, 62:202-209.

39. Strekalova T, Couch Y, Kholod N, Boyks M, Malin D, Leprince P, Steinbusch $\mathrm{H}$ : Update in the methodology of the chronic stress paradigm: internal control matters. Behav Brain Funct 2011, 7:9.

40. Strekalova T, Steinbusch HWM: Measuring behavior in mice with chronic stress depression paradigm. Prog Neuro-Psychopharmacol Biol Psychiatry 2010, 34:348-361.

41. Lamb K, Kang Y-M, Gebhart GF, Bielefeldt K: Gastric inflammation triggers hypersensitivity to acid in awake rats. Gastroenterology 2003, 125:1410-1418.

42. Smith GP, Jerome CRN: Afferent axons in abdominal vagus mediate satiety effect of cholecystokinin in rats. Am J Physiol 1985, 249:R638R641.

43. Grill HJ, Kaplan JM: The neuroanatomical axis for control of energy balance. Front Neuroendocrinol 2002, 23:2-40.

44. Caquineau C, Douglas AJ, Leng G: Effects of cholecystokinin in the supraoptic nucleus and paraventricular nucleus are negatively modulated by leptin in 24 -h fasted lean male rats. $J$ Neuroendocrinol 2010, 22:446-452.

45. Olson BR, Hoffman GE, Sved AF, Stricker EM, Verbalis JG: Cholecystokinin induces $\mathrm{C}$-fos expression in hypothalamic oxytocinergic neurons projecting to the dorsal vagal complex. Brain Res 1992, 569:238-248.

46. Gaykema RPA, Goehler LE, Lyte M: Brain response to cecal infection with Campylobacter jejuni: analysis with Fos immunohistochemistry. Brain Behav Immun 2004, 18:238-245. 
47. Chun-xia Yl, Li-qiang RU, Dao-song H: Transmission of gastric noxious signals to hypothalamus mediated by vagus nerve. Chin J Neurosci 2004, 20:353-356

48. Patel KP, Zhang K, Kenney MJ, Weiss M, Mayhan WG: Neuronal expression of Fos protein in the hypothalamus of rats with heart failure. Brain Res 2000, 865:27-34.

49. Wang X, Wang B-R, Zhang X-J, Zhen X, Ding Y-Q, Ju G: Evidences for vagus nerve in maintenance of immune balance and transmission of immune information from gut to brain in STM-infected rats. World J Gastroenterol 2002, 8:540-545.

50. Heidi EWD, Aldo B, Uslaner JM, Oates MM, Vittoz NM, Robinson TE, Watson SJ Jr, Akill H: Environmental novelty differentially affects c-fos mRNA expression induced by amphetamine or cocaine in subregions of the bed nucleus of the stria terminalis and amygdala. J Neurosci 2001, 21:732-740.

51. Emmert MH, Herman JP: Differential forebrain c-fos mRNA induction by ether inhalation and novelty: evidence for distinctive stress pathways. Brain Res 1999, 845:60-67.

52. Barbaccia ML: Much excitement about antidepressants, DBI and c-FOS. Pharmacol Res 2011, 64:333-335.

53. Rogers A, Schmuck G, Scholz G, Williams DC: c-fos mRNA expression in rat cortical neurons during glutamate-mediated excitotoxicity. Toxicol Sci 2004, 82:562-569.

54. Rogers A, Schmuck G, Scholz G, Griffiths R, Meredith C, Schousboe A, Campiani G, Williams DC: Improvements in an in-vitro assay for excitotoxicity by measurement of early gene (c-fos mRNA) levels. Arch Toxicol 2005, 79:129-139.

55. Day HEW, Kryskow EM, Nyhuis TJ, Herlihy L, Campeau S: Conditioned fear inhibits c-fos mRNA expression in the central extended amygdala. Brain Res 2008, 1229:137-146

56. Bel E, Silveira M, Graeff F, Garcia-Cairasco N, Guimarães F: Differential expression of $c$-fos mRNA and Fos protein in the rat brain after restraint stress or pentylenetetrazol-induced seizures. Cell Mol Neurobiol 1998, 18:339-346.

57. Graybiel AM, Moratalla R, Robertson HA: Amphetamine and cocaine induce drug-specific activation of the c-fos gene in striosome-matrix compartments and limbic subdivisions of the striatum. Proc Natl Acad Sci 1990, 87:6912-6916.

58. Johnstone LE, Brown CH, Meeren HK, Vuijst CL, Brooks PJ, Leng G, JA R: Local morphine withdrawal increases c-fos gene, Fos protein, and oxytocin gene expression in hypothalamic magnocellular neurosecretory cells. J Neurosci 2000, 20:1272-1280.

59. Jin BK, Franzen L, Baker H: Regulation of c-Fos mRNA and fos protein expression in olfactory bulbs from unilaterally odor-deprived adult mice. Int J Dev Neurosci 1996, 14:971-982.

60. Cullinan WE, Herman JP, Battaglia DF, Akil H, Watson SJ: Pattern and time course of immediate early gene expression in rat brain following acute stress. Neuroscience 1995, 64:477-505.

61. Larsen PJ, Mikkelsen JD: Functional identification of central afferent projections conveying information of acute "stress" to the hypothalamic paraventricular nucleus. J Neurosci 1995, 15:2609-2627.

62. Campeau S, Watson SJ: Neuroendocrine and behavioral responses and brain pattern of c-fos induction associated with audiogenic stress. J Neuroendocrinol 1997, 9:577-588.

63. Lyte M, Li W, Opitz N, Gaykema RPA, Goehler LE: Induction of anxiety-like behavior in mice during the initial stages of infection with the agent of murine colonic hyperplasia Citrobacter rodentium. Physiol Behav 2006, 89:350-357.

64. Tan Z, Nagata S: PVN c-fos expression, HPA axis response and immune cell distribution during restraint stress. J UOEH 2002, 24:131-149.

65. Girotti M, Pace TWW, Gaylord RI, Rubin BA, Herman JP, Spencer RL: Habituation to repeated restraint stress is associated with lack of stress-induced c-fos expression in primary sensory processing areas of the rat brain. Neuroscience 2006, 138:1067-1081.

66. Ostrander MM, Ulrich-Lai YM, Choi DC, Flak JN, Richtand NM, Herman JP: Chronic stress produces enduring decreases in novel stress-evoked c-fos mRNA expression in discrete brain regions of the rat. Stress 2009, 12:469-477.

67. Melia KR, Ryabinin AE, Schroeder R, Bloom FE, MC W: Induction and habituation of immediate early gene expression in rat brain by acute and repeated restraint stress. J Neurosci 1994, 14:5929-5938.

68. Ostrander MM, Ulrich-Lai YM, Choi DC, Richtand NM, Herman JP: Hypoactivity of the hypothalamo-pituitary-adrenocortical axis during recovery from chronic variable stress. Endocrinology 2006, 147:2008-2017.

69. Aisa B, Tordera R, Lasheras B, Del Río J, Ramírez MJ: Cognitive impairment associated to HPA axis hyperactivity after maternal separation in rats. Psychoneuroendocrinology 2007, 32:256-266

70. Ginsberg AB, Campeau S, Day HE, Spencer RL: Acute glucocorticoid pretreatment suppresses stress-induced hypothalamic-pituitaryadrenal axis hormone secretion and expression of corticotropinreleasing hormone hnRNA but does not affect c-fos mRNA or Fos protein expression in the paraventricular nucleus of the hypothalamus. J Neuroendocrinol 2003, 15:1075-1083.

71. Veening JG, Van Der Meer MJ, Joosten H, Hermus AR, Rijnnkels CE, Geeraedts LM, CG S: Intravenous administration of interleukin-1 beta induces Fos-like immunoreactivity in corticotropin-releasing hormone neurons in the paraventricular hypothalamic nucleus of the rat. J Chem Neuroanat 1993, 6:391-397.

72. Weiser MJ, Handa RJ: Estrogen impairs glucocorticoid dependent negative feedback on the hypothalamic-pituitary-adrenal axis via estrogen receptor alpha within the hypothalamus. Neuroscience 2009, 159:883-895.

73. Gillespie CF, Nemeroff CB: Hypercortisolemia and depression. Psychosom Med 2005, 67:S26-S28.

74. Abelson JL, Khan S, Liberzon I, Young EA: HPA axis activity in patients with panic disorder: review and synthesis of four studies. Depress Anxiety 2007, 24:66-76.

75. Condren RM, O'Neill A, Ryan MCM, Barrett P, Thakore JH: HPA axis response to a psychological stressor in generalised social phobia. Psychoneuroendocrinology 2002, 27:693-703.

76. Martin EIRK, Binder E, Nemeroff CB: The neurobiology of anxiety disorders: brain imaging, genetics, and psychoneuroendocrinology. Psychiatr Clin N Am 2009, 32:549-575.

77. Jaferi A, Bhatnagar S: Corticotropin-releasing hormone receptors in the medial prefrontal cortex regulate hypothalamic-pituitaryadrenal activity and anxiety-related behavior regardless of prior stress experience. Brain Res 2007, 1186:212-223.

78. Bethea CL, Lima FB, Centeno ML, Weissheimer KV, Senashova O, Reddy AP, Cameron JL: Effects of citalopram on serotonin and CRF systems in the midbrain of primates with differences in stress sensitivity. J Chem Neuroanat 2011, 41:200-218.

79. Young EA, Altemus M, Parkison V, Shastry S: Effects of estrogen antagonists and agonists on the ACTH response to restraint stress in female rats. Neuropsychopharmacology 2001, 25:881-891.

80. Puder JJ, Freda PU, Goland RS, Wardlaw SL: Estrogen modulates the hypothalamic-pituitary-adrenal and inflammatory cytokine responses to endotoxin in women. J Clin Endocrinol Metab 2001, 86:2403-2408.

81. Walf AA, Frye CA: A review and update of mechanisms of estrogen in the hippocampus and amygdala for anxiety and depression behavior. Neuropsychopharmacology 2006, 31:1097-1111.

82. McIntyre RS, Mancini D, Eisfeld BS, Soczynska JK, Grupp L, Konarski JZ, Kennedy SH: Calculated bioavailable testosterone levels and depression in middle-aged men. Psychoneuroendocrinology 2006, 31:1029-1035

83. McNicholas TA, Dean JD, Mulder H, Carnegie C, Jones NA: A novel testosterone gel formulation normalizes androgen levels in hypogonadal men, with improvements in body composition and sexual function. Bju Int 2003, 91:69-74.

84. Written WK: Occurrence of anoestrus in mice caged in groups. J Endocrinol 1959, 18:102-107.

85. Clarke G, Grenham S, Scully P, Fitzgerald P, Moloney RD, Shanahan F, Dinan TG, Cryan JF: The microbiome-gut-brain axis during early life regulates the hippocampal serotonergic system in a sex-dependent manner. Mol Psychiatry 2013, 18:666-673.

86. Meziane H, Ouagazzal AM, Aubert L, Wietrzych M, Krezel W: Estrous cycle effects on behavior of $\mathrm{C} 57 \mathrm{BL} / 6 \mathrm{~J}$ and BALB/CByJ female mice: implications for phenotyping strategies. Genes Brain Behav 2007, 6:192-200.

87. Võikar V, Kõks S, Vasar E, Rauvala H: Strain and gender differences in the behavior of mouse lines commonly used in transgenic studies. Physiol Behav 2001, 72:271-281. 
88. Gareau MG, Wine E, Rodrigues DM, Cho JH, Whary MT, Philpott DJ, MacQueen G, Sherman PM: Bacterial infection causes stress-induced memory dysfunction in mice. Gut 2011, 60:307-317.

89. Johnson-Henry KCNM, Avitzur Y, Mitchell DJ, Ngan B-Y, Galindo-Mata E, Jones NL, Sherman PM: Amelioration of the effects of citrobacter rodentium infection in mice by pretreatment with probiotics. J Infect Dis 2005, 191:2106-2117.

doi:10.1186/1744-9081-9-46

Cite this article as: Luo et al: Experimental gastritis leads to anxietyand depression-like behaviors in female but not male rats. Behavioral and Brain Functions 2013 9:46.

Submit your next manuscript to BioMed Central and take full advantage of:

- Convenient online submission

- Thorough peer review

- No space constraints or color figure charges

- Immediate publication on acceptance

- Inclusion in PubMed, CAS, Scopus and Google Scholar

- Research which is freely available for redistribution

Submit your manuscript at www.biomedcentral.com/submit 